\title{
ASSIMILATION AND ABORIGINAL TEACHER EDUCATION
}

\author{
*P. Roberts
}

The theories upon which the main institutions concerned with Aboriginal education rest are characterised by delusion and ethnocentrism. When we describe such institutions as 'Aboriginal', we tend to lose sight of the fact that they are essentially European creations. Most of the problems we hear about in Aboriginal education are, in this sense, European rather than Aboriginal.

This position paper is taken from a longer essay on what seems to be central to such delusion and ethnocentrism, namely the pervasive concept of assimilation. I have tried to deal with some of its meanings and relate them specifically to teacher education for Aborigines. Part of my interest in this subject comes from watching the careers of Aboriginal students who have attended white tertiary and subtertiary institutions. Young people may enrol in a course, the very first stated aim of which is "to enhance the self-image of the student". Yet, so often, the opposite happens and the student ends up graduating to jail. Most of this immense disaster, and it is truly immense, stems from the assimilationist reality of the educational offering imposed upon students.

Assimilation as attitude, as covert policy, as hidden curriculum, as reality constructed by majority to define minority existence, is resilient in Australia. Different forms of it are evident. The "symbolic universes" (Berger \& Luckmann, 1967, p.2) ${ }^{1}$ created by majorities to define the realities of migrant groups are of a different order from the social reality imposed by whites upon black groups in this country. When policies for Aborigines and migrants coincided, as they did under the banner of assimilation ten or fifteen years ago, different meanings were manifested in different legislation for Aborigines as compared with migrants, different attitudes towards each, and the imposition of different sorts of educational programs.

Today, with the policy of multiculturalism, there are numerous attempts to theorise on a general applicability to all minority groups.

* Mr Paul Roberts, Claremont Campus, Western Australia C.A.E。 Goldsworthy Road, Claremont 6010

Paper tabled at N.A.E.C. Conference on Aboriginal Teacher Education, held at Mount Lawley Campus of W.A.C.A.E。, July 1982. 
This official definition conflicts with what many Aborigines know that multiculturalism is not for them。 Rather, it is, among other things, a power base for certain migrant groups. This is not to say that it is a bad concept, but simply to note that where Aboriginal groups are concerned, their inclusion under the multicultural banner has been token. For them assimilation remains the reality.

Richardson $(1979)^{2}$ sees three meanings of assimilation arising from three different traditions.

From anthropology comes the concept of acculturation, which involves a (minority) group in changing overt patterns of behaviour or expressed patterns of beliefs and values in the direction of the mainstream culture... From sociology comes the concept of integration, which involves...entering into the social, economic and political institutions of the receiving society. Finally, from psychology comes the concept of identification, which involves a (minority) group in thinking and feeling about itself as more like the (majority) group of the resident society.

$$
\text { (A. Richardson, 1979, p.3) }
$$

Now, consider an official evaluation of Papunya, a Northern Territory community, made in $1964 .^{3}$

In 1962 I calculated that rather less than a third of the hundred families then at Papunya could be considered relatively acculturated: that is, they had had a lifetime of contact with Europeans... About 20\% were Walbiri ranging from very conservative old men...the Pintubi, now rather more than $50 \%$ of the population...are little Westernised...

I have argued elsewhere that the continued migration of unsophisticated Pintubi into what is anyway a predominantly Aboriginal community has slowed the normal acculturation process. This is one reason for establishing another community further west for the Pintubi, so that they will cease to act as a brake on the development of the rest of the Papunya people.

Almost all the Papunya people are still most reluctant even to move out of their own area and none would consider permanent emigration in my view. The first group of young men were only persuaded with real difficulty to go droving in 1958... I have pointed out elsewhere that there are 
several more sophisticated communities in Central Australia from which to date there has been no significant emigration into areas of greater developmental potential, i.e., the northern part of the Territory: Alice Springs may be considered "over saturated" as far as Aborigines are concerned.

("Social development of the Papunya people", $18 / 6 / 64)$

A book could be written in the cause of decoding the pseudoscience underlying this memo. Although it is difficult to distinguish sources, the Papunya statement has considerable input from the anthropological tradition as defined by Richardson. Its author, now at the top echelon of the Department of Aboriginal Affairs, would no longer speak of levels of sophistication or use the paternalistic language of acculturation, but the thinking remains intact. It is pervasive in the Northern Territory bureaucracies, including the Education Department. Migrants may now have their multiculturism, but Aborigines are still incarcerated in our Papunyas.

One may ask what relevance all this has to the subject of teacher education. The point I am suggesting is that peculiar, archaic, resilient and often unseen strains of the assimilationist concept are present in the form and content of the institutions in which we place Aborigines. With our history we should expect to encounter them, not only in institutions like the many Papunyas of Australia, but also in institutions like our centralised educational establishments. As Tatz $(1982)^{4}$ has noted, assimilation is "widespread in theory and practice" and means more than the simple act of swallowing. It is also a process of generalisation whereby strategies developed in metropolitan institutions are imposed upon black communities. Minority groups are forced to abandon their traditional culture and "become us". 5

The process of generalisation the majority has used to maintain, in the Bergman and Luckmann terminology, the hegemony of its symbolic universe, is, in regard to Aborigines, one of nihilation. An extreme of nihilation is represented by the massacre. In regard to what has been stated above, it is interesting that our ancestors rarely felt it legitimate to massacre immigrants. Yet they found little problem in rationalising the genocide of the indigenous people. We find it difficult to cope with these facts of our history and most of us in the majority culture are complacent enough to believe that massacres are no longer carried out. I believe they are. The official Papunya statement quoted above is all about massacre, the massacre of a culture. 
There are many lines of continuity between it and the ideology of those earlier folk who did the shooting.

The new form of nihilation is symbolic, often hidden and highly institutionalised. If teacher education programs for Aborigines are to succeed, this assimilationist minefield will have to be circumvented. A clean break will have to be made with past programs and their auras. Nihilation has always been the antithesis of strong, stable Aboriginal identity. The new teacher education programs could be important vehicles for developing such identity, that is, for freeing people.

I would like to use the Strelley Community School as a point of reference in discussing teacher education. This is because programs, including the adult ones, are in a sense the "purest", the least imposed - dare I say it - the least assimilationist, of any offering in Australia. I hope that what I mean by this odd claim will become clearer with elaboration. When writing of "Strelley", I refer in a general sense to all the Aboriginal bilingual community schools under the auspices of the Nomads Foundation. These include, among others, the schools at Noonkanbah and Warralong as well as the Strelley school. The latter was started first and many of the principles worked out there apply to all. Thus the generic term "Strelley".

The first day of school in 1976 has been described to me as follows. A hundred children lined up silently with clean clothes, shiny faces and slicked-up hair. The European teachers who had recently arrived from Perth were dismayed, not only because this event took place just after sunrise and on the day before school was scheduled to commence, but also because they felt the response was in a European stereotype. They were disappointed because their vision was of some sort of "Aboriginal" response, unclear perhaps, but certainly different from the one they received.

Today the children don't line up, neither are they conspicuous1y punctual or fastidiously dressed. The point is that the change in stereotypes has come about through continuing dialogues between blacks and whites. Programs at Strelley are not set-pieces, rather they are free-wheeling, moveable feasts. There is an on-going working out of contractual arrangements between community and teachers rather than an institutionalisation. This may sound like a subtle difference, and perhaps it is, but could it be the difference between an imposition and a happening, between failure and success? 
Teacher education has been, until recently, something of a non-program at Strelley. This is not to say that nothing was happening。 Rather many informal and low profile events occurred. Community discussions and theorising, which did not involve the European teachers, together with an increasing number of informal contacts between black and white teachers, took place. The community dealt with the issue of teacher education in its own way and in its own time frame. Different possibilities were considered and different individuals gradually slotted into school roles, some of them highly innovative, according to community directives.

All this has been a process rather than a program. Stereotypes about what a teacher education program should look like caused the European teachers considerable anxiety, particularly in the early years of the school. Where were the up and coming Aboriginal teachers? Where was the magic formula? Should they be imparting literacy skills or teaching methodology? What were the priorities? Why were decisions taken so slowly? Fortunately, due to the structure of the school, in particular the power of the school committee which is an Aboriginal decision-making body, the European teachers were not in a position to impose a direction on the programs. Adults selected by the community as teachers were, above all, trusted people. They were often, particularly in the early days, middle-aged, probably not the ones the European teachers would have selected had they had the authority to select.

There was great wisdom underlying this process. Over thirty Aboriginal teachers are now involved, outnumbering the Europeans perhaps three to one. They are teachers, not aides, even though their roles differ greatly from those of teachers in other schools. These are people who are confident about their children's future. They are not, as has been suggested, over-protected or sheltered from the white man's world. On the contrary, they appear to have a clear and incisive understanding of the workings of white society. There is wisdom and consistency, not confusion, in the way the effects of European culture on Aboriginal society are interpreted and such meanings transmitted to succeeding generations - or to anyone with listening powers. This is a dynamic and viable consciousness rather than some anachronism of static identity.

Put another way, the Strelley programs have the great virtue of balance. Things Aboriginal are balanced rather than overwhelmed by things European, formal and informal learning and teaching contents are balanced and the authority European teachers enjoy by virtue of their formal qualifications is firmly counter-balanced by the overriding power of the community's decision-making structures. This 
situation of balance is represented by the Diagram 1. The four quadrants may be seen as representing European and Aboriginal formal and informal cultural-learning factors. The shaded square is a conceptualisation of the cultural inputs in a balanced educational program.

\section{Diagram 1}

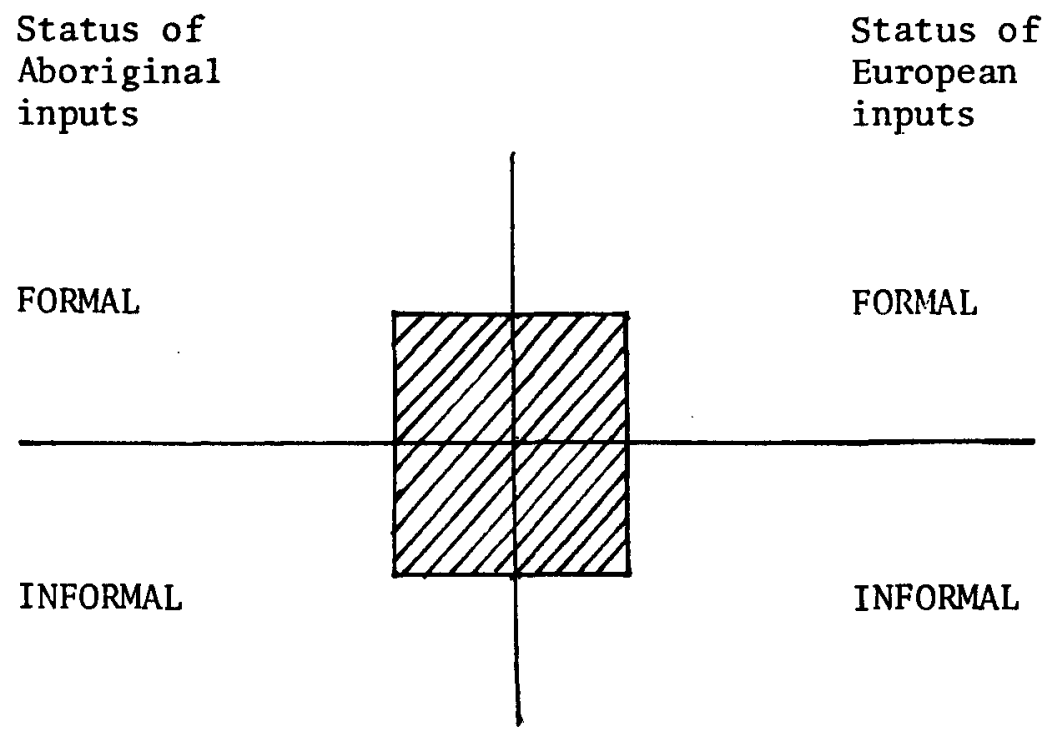

In contrast to this concept of balance, I would like to consider some of the rationales offered in the main Aboriginal teacher education programs operating in this country. My chief concern is that what has become broadly conceived as bicultural education, ${ }^{6}$ may be generically closer to the tradition of assimilation than to that of multiculturalism. This notion can be represented by arrows (Diagram 2). These arrows illustrate what could be called hidden values.

Diagram 2

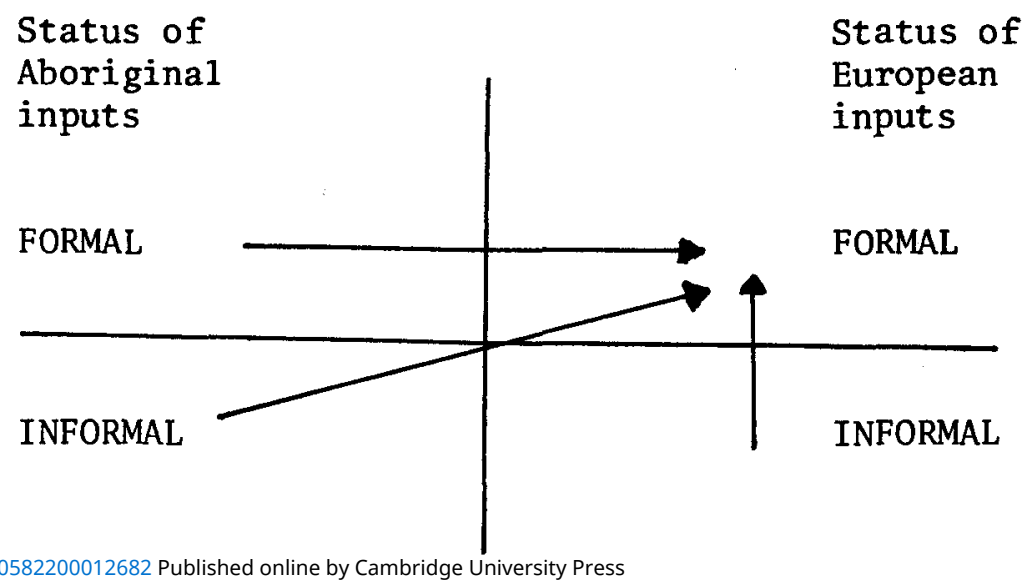


In short, this means that in an institution or a program, the formal Western area of education is accorded higher status than the other areas. Furthermore, a Western authority structure dominates the Aboriginal decision-making input. This situation contrasts with the Strelley model very much in the same way that a transfer design contrasts with the maintenance model in the old bilingual education debate. The bilingual programs operating in the Strelley schools are maintenance based. Communities view these programs as vehicles for maintaining identity. There is little or no theorising about the value of transferring to English. This is not to say that transference does not take place: there have been a number of cases of illiterate adults becoming bilingual readers in rapid time. However, this outcome could be described as an informal one and the status of the traditional language is enhanced rather than threatened.

The early bicultural programs operating in Northern Territory schools from the mid-sixties were quintessentially assimilationist. The advisers were all European. In one program, a white adviser toured Arnhem Land teaching European teachers how to teach Aboriginal children how to dance Aboriginal dances. ${ }^{7}$ Aboriginal adults selected by white school principals were brought into schools to give instruction in painting, weaving, carving and so on. European authority generally dictated who taught these classes, where, when, how and to whom. The result, not surprisingly, was the according of negative status to these Aboriginal adults and the things they taught. This alienating process, which is summed up in the Aboriginal concept of shome, may be represented by the arrows indicating hidden values -

\section{Diagram 3}

Status of Aboriginal inputs
Status of European inputs

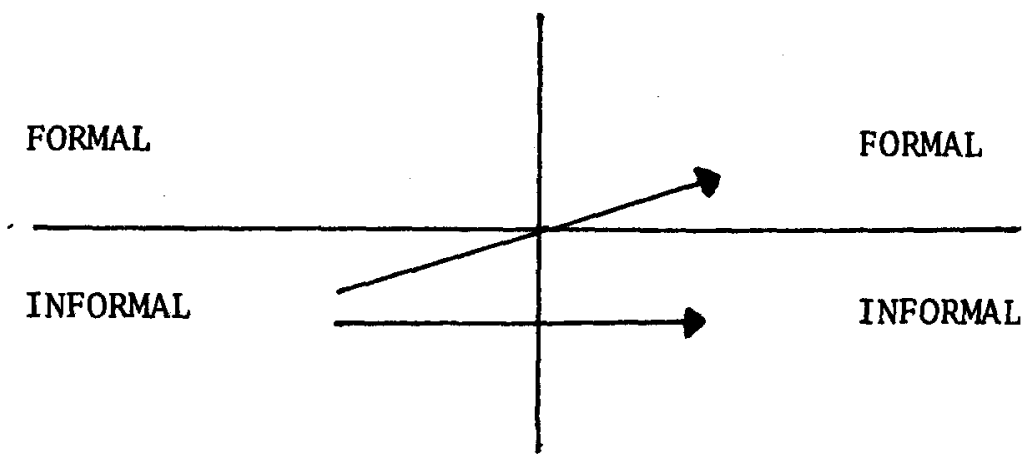


A third set of hidden values could be said to exist in the according of high status to informal areas of Western education. Thus, young people from settlements in the desert may be sent to a C.A.E. in the city to learn "recreation skills". This sort of program could be represented as in the following diagram :

\section{Diagram 4}

\author{
Status of \\ Aboriginal \\ inputs
}

Status of European inputs

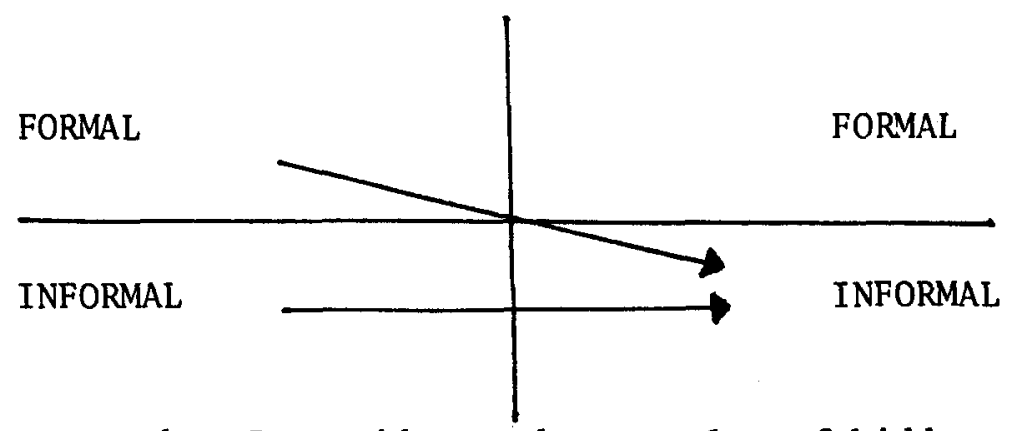

Below are what I consider to be examples of hidden values in current approaches to Aboriginal teacher education. In practice, some of them may be counterbalanced by arrows in opposite directions. Furthermore, it would be naive to consider that there should be no arrows, that status should be equitably distributed in all courses. However, if these programs are to be considered as "bicultural" and if we are to claim to have profited from past mistakes, we should be conscious of the hidden values that underlie the rationales.

1. First, consider some examples of the allocation of high status to forma1, Western, academic coursework and qualifications, as represented in Diagram 2. Anyone who has worked in an Aboriginal school or college will know how difficult it is to obtain funds or accreditation for courses emphasising informal or not easily measurable or non-academic outcomes. The strength of the vested interest in what Stephen Harris calls "Balanda thinking" is, I believe, evident not only at the high administrative levels, but also among many bicultural advocates. The Schools Commission Aboriginal Consultative Group (1975) ${ }^{8}$ recommended

...the end-point qualification of Aboriginal teachers should be at an equivalent level to that required of non-Aboriginal teachers in Australia. 
Similar statements can be found in most rationales for the enclave programs as well as for the various "bridging" courses found in C.A.E.S. A generally positive evaluation of the W.A.I.T. bridging course contains the following negative comment. 9

One of the negative outcomes of the Bridging Course is the alienation of some students from their friends and families. This may be a result of their increased status, but can also be at least partly attributed to changes in the students themselves. Their degree of sophistication, in European-Australian terms, is very apparent by the end of the Course. The Course might well include greater emphasis on the fact that students are not becoming "better" people as a result of their studies, but are merely learning cultural skills necessary for survival in the context of EuropeanAustralian sectors of Australian society. There is, perhaps, a need for greater emphasis on bi-culturalism rather than self-development, the latter having the connation that learning to present oneself in Angloapproved ways makes students "better" people.

(Stringer, 1982)

Harris 10 comments that a number of traditional Aboriginal learning styles "do not appear to have productive applications in modern classrooms." These include the perennial presenttime orientation as we11 as the trust placed in the authority of elders. I do not wish to misrepresent Harris' position: much of what he offers has to do with ways in which Aboriginal learning styles may be highly relevant and appropriate. However, the thrust of his work is hierarchical, in the same way that Piaget's developmental stages form a hierarchy. There is a clear implication that certain sorts of thinking, certain "cognitive skills", are more advanced than others. Balanda learning skills are seen as increasingly important as the student grows up, and Aboriginal (yolngu) styles as of decreasing importance.11

Furthermore, the teacher's job is seen as increasing learning efficiency by capitalising on knowledge of yolngu learning styles. They are a means rather than an end: a means towards reaching the peaks of higher, Western, problem-solving, abstract thinking. 
Whereas the works cited above are of great significance to all involved in Aboriginal education, I believe there are many hidden values in line with my second diagram involved in the thinking and many questions posed by them. For example, is there any evidence that Piaget "works" in this country, that his hierarchy of Swiss readiness is replicated, either with white or black Australians?

2. The status attached to learning certain skills is a particular aspect of the question of the status of formal Western education. Many European teachers rationalise what they teach Aboriginal students simply by alluding to a vague category called "basic skills". Aborigines are seen as lacking these skills and presumably as being in need of them. We hear of recreation skills, functional job skills, interpersonal skills and, most important, the three $R^{\prime} s$.

For example, conventional wisdom has it that Aborigines are, by and large, functionally illiterate or semi-literate and need to be numerate and 1iterate. Experienced European teachers and advisers in the Territory or Western Australia still tell the new chums not to worry too much about the fancy cultural stuff, but to go to the heart of the matter and teach them the three $R^{\prime} s$. Besides conveniently avoiding the "how" questions, this approach often rests on the assumption that skills can be taught independent of their cultural milieu. This assumption appears to underlie the rationales for bridging courses which feed into teacher education programs. The notion that there is a way of teaching skills independent of cultural factors does not bear scrutiny. There is no such thing as a culture-free skill any more than there is a culture-free I.Q. test.

3. Most of the Aboriginal teacher education programs, for example, those at Mount Lawley and Batchelor, are highly centralised. Hidden values are very much part of the rationalisation of this fact, in the colossal expenditure on building libraries, lecture theatres, dormitories and paying out air fares. Dr Penny's ${ }^{12}$ statment is a standard one of this genus:

...that Aborigines appointed as Aboriginal teachers by qualification be encouraged and enabled to take further courses, hopefully in a college of advanced education, qualifying them for higher posts in a tribal school or for appointment, if they wish, to a non-tribal school. 
Harris ${ }^{13}$ puts a different perspective on the benefits of centralisation:

The place of centralised training should be in a large town, preferably Darwin, so that teacher trainees can be exposed to the educational processes and experiences of urban life.

(S.Harris)

These are both normative statements, the second of which appears to be based on a behaviourist notion of stimulus (Darwin) - response (cultural awareness). There would appear to be little evidence to support the contention that big, centralised institutions are good places for raising Aboriginal consciousness or fostering positive identity. The high dropout rates from these institutions and an analysis of the reasons for it might provide interesting data. There is a growing weight of evidence to suggest that the institutionalisation promoted under assimilationist policies in the sixties (and seventies) was a primary cause of massive social malaise. Maybe, as Harris would have it, the institutions and courses have changed since then and need to change further. However, these arrows pointing to cities and dormitories need to be examined. One may ask if advocating this form of centralisation is substantially different from supporting the enforced incarceration of Aboriginal adolescents practised by missionaries in the fifties and sixties.

4. The recruitment of students follows on from the centralisation of courses. In the early days of Batchelor, school principals were asked to actively recruit "bright" young students and send them off. Consultation with parents and community was not regarded as a high priority. The process of recruitment continues, often in hidden forms and the process of consultation remains of a token nature. Many examples of this phenomenon could be cited from the Northern Territory or Western Australia. This is part of the unspoken internal logic of these massive institutions. There is Commonwealth money in student numbers and competition in attracting them.

Furthermore, there is a Parkinson's law about the institutions. Once the buildings are there, courses and students are found to fill them. It is a perverted sort of logic which contrasts strongly with the Strelley mode1. There is no Aboriginal timeframe about the courses offered. Rather, there is a headlong rush for students and funds in which the welfare of the student client becomes a secondary issue. 
5. In the centralised institutions, many hidden values exist according to the pattern in Diagram 4. One of these relates to the availability of alcohol. Very often the rationale is given that students should be exposed to alcohol along with all the other good and bad aspects of European culture. The institution has no business to intervene, even if home communities wish it would.

Again, there appears to be a peculiar logic underlying this sort of approach. The institution rather than the student's family, is seen as knowing what is best for him. Is there any evidence to suggest that an unrestricted exposure to alcohol or for that matter, the mixing up of girls and boys in European configurations has been beneficial to Aboriginal students?

6. Tokenism, in the pattern of Diagram 3, is also a major factor in the hidden assimilationist underpinnings of some of the Aboriginal teacher education courses. We still have European experts teaching Aboriginal students about Aboriginal culture. A hidden curriculum develops which allocates negative meanings to traditional ways. Aboriginal culture is presented more as a museum piece than as a viable way of life. Although there have been moves to lessen the paternalism inherent in this content, the academic empires that have been established in the institutions mitigate against such reform.

To conclude, the hidden values $I$ see in much of the theory and practice of Aboriginal teacher education are founded in a mainstream assimilationist tradition. They are part of an "inevitability syndrome". Just as Daisy Bates felt it inevitable that Aborigines would die out, so did the early assimilationists hold it inevitable that Aborigines would "become us". Such thinking has left its mark in the narrow and blinkered conceptualising about social change we find embedded in our institutions.

This paper could be said to be slanted towards traditionallyoriented Aborigines. I hope, however, it has some wider relevance: whereas some Aborigines may wish to be assimilated and others may have identities strong enough to withstand the outrageous arrows of European institutions, there must be another large group that, given different alternatives, would be much happier about the process of becoming teachers. 
At this time I can see no developing Aboriginal pedagogy which would herald such a process of change. I have used the Strelley model as a reference point because the Aboriginal people there are articulating, for those who have ears to listen, something that may well become the basis for such a pedagogy. People bound up in their institutional realities find it very difficult to listen to their story. The strength of the education system at Strelley rests in Aboriginal power. Without a vastly increased Aboriginal power over schools and other institutions, no Aboriginal pedagogy will be more than a stunted hybrid.

\section{REFERENCES}

1. Berger, P. and Luckmann, T., 1967: The Social Constmuction of Reality. New York, Anchor.

2. Richardson, A., 1979: The assimilation and adjustment of immigrants. In R. Johnston (Ed.): Immigrants in Western Australia.

3. Social Development of the Papunya People. Memo dated 18/6/64 to Northern Territory Director of Welfare, Department of Aboriginal Affairs Library, Darwin.

4. Tatz, C., 1982: Aborigines and Uranium and Other Essays. Melbourne, Heinemann. (p.62)

5. Ibid.

6. Harris, S. and Christie, M.: Bicultural education - towards a definition. In D.J.McClay, S.G.Harris \& M.J.Christie (Eds): Teaching in Amhem Land. Publication pending.

7. From Northern Territory Education Department files: "Snake Bay", circa 1964.

8. Education for Aborigines. Report to the Schools Commission of the Aboriginal Consultative Group, 1975, p.17.

9. Stringer, E., 1982: An evaluation of the WAIT Aboriginal bridging course. Faculty of Education, W.A.I.T., p.35.

10. Harris, S.: Aboriginal learning styles and the three R's. p.10, (no publishing details given).

11. Harris and Christie, op. cit.

12. Quoted from Accreditation Proposal, Darwin Community College, July 1980, p. 12 .

13. Ibid., p.13. 